\title{
Evaluating the Effectiveness of ATI-RTC XI Learning Sites and Schools for Practical Agriculture in Region XI
}

Gilbert M. Gordoํㅡ, Gilbert A. Importante ${ }^{2}$, Angelo E. Jadraque ${ }^{1}$, Rey A. Castillo', William M. Felisarta², Robert C. Satorre ${ }^{3}$

\begin{abstract}
The Department of Agriculture-Agricultural Training Institute is continually keeping up with the challenges on the implementation of its extension programs. This study elaborates on the effectiveness of the Learning Sites (LS) and School for Practical Agriculture (SPA) in delivering technologies to farmers. Mixed methods approach was used to generate qualitative and quantitative measures. These included the conduct of focus group discussion, survey, and field visits. There were 10 participants in the FGD and 154 respondents for the survey. Regression analysis was used to explain the determinants of the effectiveness of established program objectives. Return on investment and value for money estimates showed that farmers' income increased. Moreover, the sufficiency of inputs and conduciveness of the facilities were found to directly relate to program success. Consequently, the implementation of LS and SPA is deemed effective and sustainable.
\end{abstract}

Keywords: learning sites, practical agriculture

1 Faculty, College of Governance and Business, University of Southeastern Philippines

2 Faculty, College of Teacher Education and Technology, University of Southeastern Philippines

3 Former Science Research Specialist, Southern Mindanao Agriculture, Aquatic and Natural Resources Research and Development Consortium

Contact the lead author at g.gordo@usep.edu.ph 
The agriculture sector remains to be one of the most challenging sectors to develop. While faced with various challenges such as increasing population, conversion of agricultural lands to residential and industrial lands, climate change, downtrend in students enrolled in agriculture courses, the country is steadfast in ensuring that food will be on the table (Agricultural Training Institute, Department of Agriculture, 2017). Keeping up with these challenges includes the design and implementation of extension projects to maintain dedicated farmers who use appropriate technologies that help increase their earnings. Responsibility over the Department of Agriculture's extension initiatives lies with the Agricultural Training Institute (DA-ATI). Among DA-ATI's extension programs is the ladderized approach to ATI Extension Services. This involves the selection of Learning Sites (LS), Schools for Practical Agriculture (SPAs) and Private Extension Service Providers (P-ESPs) to become partners in DA-ATI's extension initiatives (ATI, nd). While funds are provided to support this initiative, design and implementation alone do not guarantee that objectives have been met. Both periodic monitoring and evaluation activities are necessary. The Manual in the Establishment of Learning Sites (LS) and Schools for Practical Agriculture (SPA) (2017) in fact requires that quarterly monitoring and annual evaluation must be undertaken by DA-ATI.

This study was conducted to evaluate the effectiveness of the LSs and SPAs as DA-ATI's partners in delivering extension services and to describe determinants of effectiveness which are equated to return-ofinvestment (ROI) and value for money (VfM) analysis.

\section{The many dimensions of effectiveness}

Effectiveness can mean differently to different organizations (Cameron, 1980). It has been broadly defined as the extent to which goals, objectives, or impacts have been met or achieved (Low and Soo, 
1980; Bourn, 2007). Previous approaches to defining organizational effectiveness may be classified as either goal model, system resource model, process model, or ecological or participant satisfaction model (Lowe and Soo, 1980; Cameron, 1980). More recent models, however, took even broader approaches in monitoring of performances and attainment of goals by considering internal and external factors (van der Heever and Coetsee, 1998) or considering both financial and nonfinancial measures (Bernard, 2000; Manoochehri, 1999; Yaghoobi \& Haddadi, 2016).

\section{Factors affecting effectiveness}

Several factors have been identified to affect or influence organizational effectiveness. Using a systems approach to defining effectiveness, van der Heever and Coetsee (1998) identified values of organizational members, technology and funding, in addition to the categories of organizational inputs, transformational aspects, organizational outcomes, attributes, and social responsibility derived from several literature.

Knowledge management which involves the "creation, storage, distribution, and application of knowledge" provides a moderating role among training and organizational effectiveness (Rahman, Ng, Sambasivan, \& Wong, 2013) and culture (Smith \& Kleiner, 1987). On the aspect of training, quality trainings provided by extension programs may be affected by post-training activities (Jones, 2014); trainers' abilities (Bobinski, 2014; Ziman, 2017); training plan, delivery and materials (Root III, 2017; Bobinski, 2014; King, 2012; Urquhart, 2011 Ziman, 2017); training facility (Veenapoosa, 2016); and proximity of training location (Chatty, Baas, \& Fleig, 2003). 
Other internal and external factors that may positively or negatively impact on effectiveness include "other organizational activities, market forces, competitive activity, new technology, legislation, economy, industrial action, conflicting internal priorities, and resistance to change" (Bernard, 2000).

Non-government institutions, on the other hand, are assessed in terms of attainment of its purpose (Des Rosierss, 2014). In addition, impact could be measured in terms of program reach, poverty alleviation, degree of participation, financial and institutional sustainability, "costeffectiveness, innovation and flexibility, replicability and scalability, gender impact, environmental impact, and impact in terms of advancing democracy, pluralism and civil society" (Cannon, 2013).

\section{The Philippine agriculture scene and factors hampering program effectiveness}

Limited resources on the part of training recipients hamper the effectiveness of training programs in agriculture. Aside from problems with resources is the decline in farm sizes which has resulted to inefficiencies as farmers are not able to take advantage of economies of scale (PCCARD, n.d.). A cause for the decline in farm lands is the encroachment of housing projects and industrial estates and land banking done by large companies (Gamboa, 2017). The decline of population and the increase of aging farmers have also contributed to challenges in learning and adopting new farming technologies (Villar, 2017). Other contributory factors that impact on the effectiveness of programs are the limited number of extensionists according to Paras (as cited in PCCARD, n.d.) and personal motivation of the farmers themselves (Gamboa, 2017). 


\section{Return on Investment and Value for Money Analysis}

Return on investment (ROI) is considered one of the most popular efficiency performance measure and evaluation metrics used by businesses. This requires measuring the total return that an organization has provided to its investors (Brigham, 2015). This is calculated by dividing the benefit (return) of an investment by the cost of the investment and is usually expressed as a percentage or a ratio (Botchkarev \& Adru, 2011). While businesses may be required to reach industry levels of ROI when looking at projects, government agencies (or projects) do not have to be evaluated in the same manner given their mandate to provide public service (Applied Geographics, Inc., 2009).

Literature suggests several approaches to value for money (VfM) analysis. In fact, there appears to be as many approaches as there are many types of programs or industries being studied. Generally, VfM refers to four interrelated concepts of economy, efficiency, effectiveness (Jackson, 2012; ICAI, 2011), and equity (ICAI, 2011) in attaining desired outcome. It then involves evaluating whether the program got the best value inputs, maximized the outputs for a given level of inputs, ensured that the outputs were able to deliver the desired outcome, and ensured that the benefits were distributed fairly (ICAI, 2011). Some studies though have been more specific in their VfM approaches. The UK's Department for International Development, for example, suggested looking at the impact of the program in improving "poor people's lives" considering the desired quality and prices (DFID, 2011). In the construction industry, VfM meant completing projects at the earliest time, at the lowest cost and without compromising its quality (Egginton, 2011). With government projects, this meant savings in terms of quality improvement in administration and in-service delivery or, generally, desired outcomes (OECD, 2011; Bourn, 2007). Closely 
related economic valuation, cost-benefit analysis and cost-effectiveness approaches have also been widely used (Sorenson, Drummond, \& Kanavos, 2008) although some concerns over reliability of results have been raised given the need to make assumptions when quantifying relevant costs and benefits (Bourn, 2007; Grimsey \& Lewis, 2005 as cited in OECD, 2008).

\section{The study's Theoretical Frame}

A notable work in monitoring and evaluating extension programs is that of Bennett (1975). This approach suggested a seven-tier hierarchy of evidences that allows evaluating outcomes incrementally. Roberts and Coutts (2007) suggested fusing both frameworks by coming up with a table that classifies Bennett's hierarchy into four evaluation levels of broader impact (social-economic-environmental outcomes); direct effects (practice changes; knowledge, attitude, skills, aspirations - KASA - changes; reactions, people involvement); internal project factors (activities/processes; resources); and outside project control (context; climate; policies; related projects).

For this study, the Logical Framework, Bennett's hierarchy and Roberts and Coutts' (2007) frame were combined considering the external factors (context, policies, climate and related projects) and direct effects of interventions (people involvement, reactions and change in practice) to measure the impact (socio-economic and environmental outcomes) of the interventions. 


\section{Methodology}

This study used a mixed methods approach that was conducted sequentially. First, desk research was done to identify factors that allow measurements of the effectiveness of ATI interventions on LSs and SPAs. These factors were verified and validated through focus group discussion (FGD) represented by the various stakeholders (ATI personnel, LS and SPA owners, and farmer beneficiaries). The result of the FGD was used to develop a questionnaire for the survey to be conducted among the LSs and SPAs in Region XI. To validate the results of the survey, the research team conducted field visits for purposes of triangulation and to confirm the results of the survey.

There were 154 respondents who provided responses on the effectiveness of the program. Sixty-six (66) were from LSl (Learning Site 1) while 88 were from LS2/SPA. With 18 learning sites and schools visited, the research was able to gather an average of nine (9) respondents per LS/SPA.

Results were statistically analyzed; specifically, regression analysis was used to find the ability of identified factors to explain the effectiveness of the LS and SPA The aggregate effectiveness score was derived using the average of the general rating and the four other indicators of effectiveness. Aggregate scores for each of the factors were also derived using the items assigned to each of the factors. Missing responses were not included in the computations. Three regression estimates were computed, one each for LS1, LS2, and SPA. Estimates of the computed regression equations were used to determine the effectiveness scores. Means for each of the three factors (inputs, conduciveness, and personal capabilities) were derived and plugged into the regression equations. 
The return of investment (ROI) was computed using the standard formula,

$$
R O I=\frac{\text { Income }}{\text { Cost }}
$$

For Value for Money (VfM), benefit-cost ratio was computed due to the limited data.

\section{Results and Discussion}

Factors Affecting the Effectiveness of Learning Sites (LS) and Schools for Practical Agriculture (SPA)

\section{Budget constraint and control}

From the ATI-RTC XI participants, they identified budget constraint as the main factor that affected the effectiveness of LS/SPAs. This factor hampered the probable addition of more learning sites and schools for practical agriculture; it likewise limited the number of personnel who would have been doing monitoring and evaluation. Occasionally, monitoring audits are led by the head office personnel which resulted to difficulties in assessing outcomes due to their limited time and lack of personnel. Another consequence of budgetary constraint was the limited number of scheduled training being supported by ATI. Additionally, the change in the mode of releasing the grants to LS/SPAs from cash to "in kind" have considerably slowed down the process of releasing funds, especially due to delays brought about by procurement requirements. 


\section{Seeing the technology and perceived improvement in farming abilities}

Table 1 shows that from among survey respondents, those who visited the learning sites expectedly gave high marks to seeing the showcased agriculture technology. Respondents from LS2/SPA found the program effective because they perceived an improvement in their farming abilities.

Table 1. Effectiveness Indicators' Scores for LS1, LS2/SPA

\begin{tabular}{|l|c|c|}
\hline \multicolumn{1}{|c|}{ Criteria for Assessment } & LS1 & $\begin{array}{c}\text { LS2/ } \\
\text { SPA }\end{array}$ \\
\hline Showcased applicable agriculture technology & 8.77 & 9.43 \\
\hline Resulted in improvement in farming abilities & 8.64 & 9.52 \\
\hline $\begin{array}{l}\text { Encouraged to be in the same business or have increased } \\
\text { their earnings }\end{array}$ & 8.56 & 9.43 \\
\hline $\begin{array}{l}\text { Have actually applied the knowledge or skills observed or } \\
\text { gained from the LS or LS/SPA (percentage of respondents) }\end{array}$ & $98.4 \%$ & $97.8 \%$ \\
\hline
\end{tabular}

A high average mark was also given by respondents coming from LS2/ SPAs with regard the delivery of trainings. Item from Table 1 showed that most of the respondents were able to apply knowledge or skills observed or gained from the trainings (regardless whether the training was about the commodity being promoted at the LS2/SPA or not).

\section{Knowledge and skills improvement, and conducive facilities for learning}

Table 2 shows the average scores for each of the three identified factors that have impact on the effectiveness of the LS1 and LS2/SPA. It is evident that farmers' personal capabilities were limiting factors in gaining higher effectiveness scores. 
Table 2. Factors' Scores Affecting the Effectiveness of the Program

\begin{tabular}{|l|c|c|}
\hline \multicolumn{1}{|c|}{ Criteria for Assessment } & LSl & LS2/SPA \\
\hline Inputs for knowledge and skills improvement & 8.73 & 8.97 \\
\hline Conduciveness of facilities for learning & 8.20 & 9.61 \\
\hline Personal capabilities & 6.07 & 6.69 \\
\hline
\end{tabular}

\section{Significant factor for LS1: Learning new knowledge and $\underline{\text { skills }}$}

Table 3 shows the results of the regression analysis for effectiveness from LS1 farmers. Using the three factors of inputs for knowledge and skills (inputs), conduciveness of the facility for learning (conduciveness), and personal capabilities (personal), $F(3,54)=26.99, p<0.00$, indicate a highly significant relationship between the three factors and the dependent variable in terms of effectiveness. The adjusted value was 0.56804 indicating that about $57 \%$ of the variance in effectiveness was explained by the three factors. This may even be considered high given the crosssectional data and the broad fields and agricultural background of the farmers in different areas in Region XI. It may be noted that only inputs was found to be highly significant with $p<0.00$. Given the nature of LS1, it would be more likely that farmers perceive or measure effectiveness in terms of expectations on learning about (new) technology and the skills required when using the technology. 
Table 3. Regression Results for LS1

\begin{tabular}{|l|c|}
\hline Variable & $\beta$ \\
\hline Intercept & $2.69438^{*}$ \\
\hline Inputs & $0.73936^{*}$ \\
\hline Conduciveness & -0.09137 \\
\hline Personal & 0.03121 \\
\hline
\end{tabular}

Adj $R^{2}=0.56804, F(3,54)=25.99, p<0.00$

$* p<0.00$

\section{Significant factor for LS2: Conduciveness of site's learning facilities}

On the other hand, Table 4 presents a slightly different result for LS2. Using the three factors inputs, conduciveness, and personal, $F(3,35)$ $=12.71, p<0.00$, results yielded the same highly significant relationship between the factors and the effectiveness measure. The adjusted $R^{2}$ value was 0.48044 indicating that about $48 \%$ of the variance in effectiveness was explained by the three factors. Considering the use of cross-sectional data and the likely broad fields or agricultural background of these farmer respondents, result may still be acceptable. For LS2, the factor was the only significant explanatory variable with $p<0.00$. As it does not fully operate as an SPA, farmers simply put importance in the conduciveness of the LS2 in terms of its learning facilities and its proximity from the farmers' own lands. 
Table 4. Regression Results for LS2

\begin{tabular}{|l|c|}
\hline Variable & $\beta$ \\
\hline Intercept & $3.26261^{*}$ \\
\hline Inputs & $0.715218^{*}$ \\
\hline Conduciveness & $0.48340^{*}$ \\
\hline Personal & 0.03001 \\
\hline
\end{tabular}

Adj $R^{2}=0.48044, F(3,35)=12.71, p<0.00$

\section{Significant factor for SPA: Inputs and Conduciveness}

Regression results for SPAs are shown in Table 5. Using the three factors inputs, conduciveness, and personal, $F(3,36)=57.00, p<0.00$ results show a highly significant relationship between the three factors and the effectiveness measures. This, in fact, is supported by a high adjusted $R^{2}$ at 0.81158 indicating that about $81 \%$ of the variance in effectiveness can be explained by the factors. All three factors were found to be significant with $p<0.00$. Interestingly, both inputs and conduciveness were positively related to effectiveness. Both factors would also have about the same impact on effectiveness, if any improvement is done. This meant that any improvement in the way that knowledge and skills are imparted to farmers would increase the SPA's effectiveness. The same would be true when bigger or better facilities are available for farmers for their training needs. The factor personal, however, was found to be negatively or inversely related to effectiveness. While seemingly odd, it actually showed that existing SPAs would be ineffective (or less effective) for farmers who already possess more in terms of facilities and equipment, whose farms are suitable for the technology they get trained on, who have more financial resources, who have more access to financial resources, and who already have advanced technical knowhow. 
Table 5. Regression Results for SPAs

\begin{tabular}{|l|c|}
\hline Variable & $\beta$ \\
\hline Intercept & $1.71065^{*}$ \\
\hline Inputs & $0.44096^{*}$ \\
\hline Conduciveness & $0.53246 *$ \\
\hline Personal & $-0.16063^{*}$ \\
\hline
\end{tabular}

Adj $R^{2}=0.81158, F(3,36)=57.00, p<0.00$

* $p<0.00$

\section{Return on Investment}

Both ROI and VfM were derived by evaluating the amount granted by ATI to each of the LS/SPA cooperators against farmers' earnings or its increment. ATI-RTC XI disclosed that some LS/SPAs nowadays actually earn some "disturbance fees" for catering services and provision of training hall and dormitory type facilities. They added the need to include monitoring and related expenses to costs.

Conservatively, $\mathrm{ROI}=0.16$ or $16 \%$ for LS2 respondents should be over a single period and should be about $81 \%$ in five years (or the life of the contract with LS/SPA cooperators). In peso terms, this would redound to an average increment in income per farmer of about P18,571.00 in one year. The ROI $=0.58$ or $58 \%$ for SPA respondents should be for one year and should be about $287 \%$ in five years. In peso terms, this would be an increment of about P31,364.00 in one year. Considering both LS2 and SPA respondents, the ROI $=.28$ or $28 \%$ should be in one year or about $138 \%$ over five years. This shows well spent money for ATI considering the term deposit rates of only $2 \%-3 \%$ per annum. 


\section{Value for Money}

Data gathered from ATI, LS/SPA respondents and the LS/SPA cooperators did not allow a VfM analysis here. Highlighted instead are information that would point to some additional benefits and would have undergone valuation techniques had data been available for the study.

From a value-adding perspective, the Program has certainly created improvements that may be translated into economic benefits accruing to both LS/SPAs and the farmer-training recipients. These benefits are the following: a) eventual shift from manual to semi-automated processes by integrating new technology; b) use of organic fertilizer and production of organic products that contributed to better human health; c) ability to increase the number of workers brought by an increase in production capacity and cash flow levels; d) reduction in operational costs as observed in most of those involved in vermicast production and those who produce their own concoctions to replace "medicinal" requirements of animals; e) introduction of newly developed or improved products to the market; and f) technology transferred by the LS/SPA created an even bigger impact to the communities they served.

This study further looked into the details to verify impact of the intervention through three case points cited as follows:

"Vermicomposting, vermi tea, and goat raising project initially funded by the Program has now been replicated in a project supporting 10 people's organizations with additional funds from the Department of Agriculture and the LGU. Trainings have been successful because of successful adopters that rose from LS to SPA." - LGU A

"Adoption of vermicomposting, goat raising, and organic rice/vegetables production technologies was quite evident already. The LGU, in fact, had a hard time gathering 
substrates for vermicomposting because the farmers themselves were using these for their own requirements in vermicomposting. Farmers were expected to have had some cost-savings in terms of transportation or travel costs since they used to buy inorganic fertilizers for their requirements." - LGU B

"Since most of the produce for organic vegetables were actually bought by the farm's eighty employees and the surrounding communities, they did not have to go to the market anymore. This may be translated into cost-savings in terms of transportation costs on top of the benefits of consuming organic foods. The bigger business of coco sugar and syrup production has already transformed the lives of many coco harvesters as they now have to be regularly 'harvesting'. Being an established exporter of coco sugar and syrup, the farm became a consolidator especially of coco syrup. This is translated to cost-savings for coconut farmers as they did not have to create their own markets anymore." Agricultural Scientist A

\section{Summary and Recommendations}

ATI-RTC XI's implementation of the Program clearly exceeded its targets, and possibly expectations, based on the number of visitors and the benefits that were accrued to the farmer-trainees. The number of visitors has averaged 25 per month - for those LS/SPA cooperators who submitted reports. The ROI (and VfM) estimates also appeared to be on the high side even when the computations were made using conservative assumptions. 
Some suggestions, however, appear appropriate if only to help improve further on the quality side. While quantities are laudable, it would be practical to look at the following areas that may help even further farmer beneficiaries and LS/SPAs in reaping benefits from the Program: 1) choice of cooperators; 2) monitoring and evaluation; and 3) report and documentation.

Choice of cooperators. The review team/researchers were made to understand that the choice of cooperators is supposed to be deliberated so as to promote representative crops and new technologies that may be shared to other farmers in the different municipalities in the region. It was a bit difficult to appreciate, however, how some cooperators were given the LS or SPA status when they have not built enough capability or are not prepared yet in terms of sharing or promoting these new technologies.

Monitoring and evaluation. The review team concurs with ATI-RTC XI's own assessment of their need for additional personnel for monitoring and evaluation. The monitoring and evaluation task is on top of some of ATI-RTC XI's duties. Nonetheless, more regular LS/SPA site visits coupled with some surprise visits should be done to keep cooperators on their toes. This could track or anticipate problems faced by some LS and SPA. Some of these LS/SPAs venture into other businesses, and while this is not entirely wrong it could be detrimental to the Program if resources are realigned or if the focus/attention is shifted to other businesses.

Report and documentation. Regular reports from LS/SP cooperators are necessary. It may be better, in fact, if financial reports or any of those that require cooperators to disclose information about the size and scope of their operations on a periodic basis are submitted. The tracking report for the number of visitors may also be improved if those visitors could 
be identified in terms of their purpose - whether they are there for the technology at the farm and thus related to the Program or for some other purpose. It would be good as well to include some information related to the visitors' existing business or farm (size, location, etc.) and even contact numbers that could be used by ATI-RTC XI or any other reviewer for validation purposes. 


\section{References}

Agricultural Training Instituion, Extension Programs, Projects, and Partnerships. (n.d.). Retrieved July 2017, from Agricultural Training Institute, Department of Agriculture: http://ati.da.gov.ph/ati-main/programs/extensionprograms-projects-partnerships

Agricultural Training Institute, Department of Agriculture. (2017, May 16). Manual in the Establishment of Learning Sites (LS) and Schools for Practical Agriculture (SPA). Agricultural Training Institute, Department of Agriculture.

Applied Geographics, Inc. (2009). Advancing Statewide Spatial Data Infrastructures in Support of the National Spatial Data Infrastructure (NSDI). Retrieved from https://www.fgdc.gov/initiatives/50states/ newspbp/EconomicJustification_ROI-CBA-Tutorial_v2_052809_ FinalVersa.pdf

Babonski, D. (2014). The Key to a Quality Training Program. Retrieved October 30, 2017, from http://www.management-issues.com/opinion/6187/ the-key-to-a-quality-training-program/

Bennett, C. (1975, March/April). Up the Hierarchy. Journal of Extension, $7-12$.

Bernard, R. (2000). Evaluating Oganizational Effectiveness. Industrial and Commercial Training, 32(7), 245-248.

Botchkarev, A.\& Adru, P. (2011). A Return on Investment as a Metric for Evaluating Information Systems: Taxonomy and Application. Interdisciplinary Journal of Information, Knowledge, and Management, 6, 245-269.

Bourn, S. J. (2007). Public Sector Auditing, Is it Value for Money. England: John Wiley \& Sons, Ltd.

Brigham, E. F. (2015). Fundamentals of Financial Management (8th ed.). Florida: South Western, Cengage Learning. 
Cameron, K. (1980). Critical Questions in Assessing Organizational Effectiveness. Organizational Dynamics, 66-80.

Cannon, C. (2013, February). ALNAP Overseas Development institute. Retrieved from http://idsa02.pbworks.com/w/file/fetch/74298527/ Evaluating\%20NGOs\%20(Methodology\%20Paper)_EN.pdf.

Chatty, D., Baas, S., \& Fleig, A. (2003). A Training of Trainers Source Book Based on the Principles of Participatory Methods and Approaches.

Dess. G.G., Lumpkin, G., Eisner, A.B. \& McNamara, G. (2014). Strategic Management: Creating Competitive Advantages. 7e. New York, USA: McGraw-Hill Education.

DFID. (2011). DFID's Approach to Value for Money (VfM). London: UK Department for International Development. Retrieved from https;/ / www.gov.uk/government/uploads/system/uploads/attachment_ data/file/67479/DFIDapproach-value-money.pdf

Egginton, A. (2011). Civil Engineering Projects: What is the Value for Money? London: ICE Publishing.

Gamboa, R. (2017, August 8). Perhaps, Some Hope for PHL Agriculture. The Philippine Star. Retrieved October 30, 2017, from http://www. philstar.com/business/2017/08/08/1726295/perhaps-some-hopephl-agriculture

ICAI. (2011). ICAI's Approach to Effectiveness and Value for Money. Retrieved from http://icai.independent.gov.uk/reports/icaisapproach-effectiveness-value-money

Jackson, P. (2012). Value for Money and International Development: Deconstructing Myths to Promote a More Constructive Discussion. The OECD Development Assistance Committee. Retrieved from https://www. oecd/development/effectiveness/49652541.pdf 
Jones, G. (2017). 8 Key Elements of an Effective Training Program. Retrieved October 30, 2017, from http://www.cos-mag.com/personal-processsafety/columns/8-key-elements-of-an-effective-training-program/

King, G. (2012). Handbook for the Training of Panel Members for External Quality Assurance Procedures. European Consortium for Accreditation in Higher Education.

Kumar, R. (2017). Strategic Financial Management Casebook. Dubai: Elsevier, Inc.

Lowe, E.A. \& Soo, W.F. (1980). Organisational Effectiveness - A Critique and Proposal. Managerial Finance, 6(1), 63-77.

Manoochehri, G. (1999). Overcoming Obstacles to Developing Effective Performance Measures. Work Study, 48(6), 223-229.

OECD (2008). Public-Private Partnerships: In Pursuit of Risk Sharing and Value for Money. OECD Publishing.

OECD. (2011). Value for Money in Government: Denmark 2011, Value for Money in Government. OECD Publishing.

PCCARD. (n.d.). Agriculture Machinery Information Network: Problems, Issues and Constraints. Retrieved October 30, 2017, from http:// www.pcaarrd.dost.gov.ph/home/momentum/agmachin/index. php?option $=$ com_content\&view $=$ artcile $\&$ id $=297$ :problems-issuesand-constraints\&catid $=126 \&$ itemid $=286$

Rahman, A.A., Ng, S.I. Sambasivan, M.,\& Wong, F. (2013). Training and Organizational Effectiveness: Moderating Role of Knowledge Management Process. European Journal of Training and Development, 37(5), 472488.

Roberts, K., \& Coutts, J. (2007). Methods, Monitoring, Evaluation and Reporting of Extension. Draft Proceedings - APENFORUM, 138. 
Root III, G. (2017). 7 Rules of a Successful Training Program in a Business. Retrieved October 30, 2017, from http://smallbusiness.chron. com/7-rules-successful-training-program-business-601.html

Smith, G.R., \& Kleiner, B.H. (1987). Differences in Corporate Cultures and their Relationship to Organizational Effectiveness. Leadership \& Organizational Development Journal, 8(5), 10-12.

Sorenson, C., Drummond, M., \& Kanavos, P. (2008). Ensuring Value for Money in Health Care - The Role of Health Technology Assessment in the European Union (World Health Organization). United Kingdom: MPG Books, Ltd.

Urquhart, J. (2011). How Long Should a Guest Speaker Speak? Retrieved October 30, 2017, from http://www.idoinspire.com/blog/bid/53730/HowLong-Should-a-Guest-Speaker-Speak

van der Heever, P., \& Coetsee, L.D. (1998). An Expert System-Based Audit Instrument to Assess Organizational Effectiveness. Organizational Development Journal, 16(1), 29-44.

Vennapoosa, C. (2016). How to Create Seminar Conducive Environment? Retrieved October 30, 2017, from http://www.exorsys.com/career-center/ seminar-strategies/how-to-create-seminar-conducive-environment. html

Villar, M. (2017). Of Aging Farmers and Food Security. Business Mirror. Retrieved October 30, 2017, from https://businessmirror.com.ph/ of-aging-farmers-and-food-security/

Yaghoobi, T., \& Haddadi, F. (2016). Organizational Performance Measurement by a Framework Integrating BSC and AHP. International Journal of Productivity and Performance Management, 65(7), 959-976.

Ziman, B. (2017). What Makes a Training Program Effective? Retrieved October 30, 2017, from https://www.isixsigma.com/training/ training-materials-aids/what-makes-training-program-effective-andsuccessful/\#comments 